\title{
PERKEMBANGAN PRODUCT TOSHIBA
}

\author{
RISKI MEKA \\ 185100051 \\ Fakultas Komputer \\ riskimeka.student@umitra.ac.id
}

\begin{abstract}
Toshiba memiliki dua landasan yakni dua perusahaan yang menjadi hal ihwal lahirnya Toshiba. Pada tahun 1875 berdirilah Tanaka Seizo-sho (Tanaka Engineering Works) yang merupakan perusahaan manufaktur dan telegrafis Jepang pertama. Pendirinya, Hisashige Tanaka, terkenal atas pemuda yang inovatif dengan menciptakan boneka bermesin dan jam abadi. Pada tahun 1904, di bawah nama perusahaan Shibaura

Seisaku-sho (Shibaura Engineering Works), perusahaannya menjadi perusahaan manufaktur dan peralatan listrik berat terbesar di Jepang. Pada tahun 1890, Hakunetsu-sha \& Co., Ltd didirikan sebagai perusahaan Jepang pertama untuk produk lampu pijar listrik. Diversifikasi dilakukan oleh perusahaan dengan mengembangkan bisnis ke kategori produk konsumen (consumer products). Di tahun 1899, perusahaan berganti nama menjadi Tokyo Denki (Tokyo Electric Co.). Kedua perusahaan besar yang menjadi leader pada bidangnya tersebut memutuskan untuk bergabung pada tahun 1939 membentuk satu perusahaan manufaktur peralatan listrik, Tokyo.

Shibaura Denki (Tokyo Shibaura Electric Co., Ltd.). Perusahaan tersebut kemudian lebih terkenal dengan nama Toshiba yang menjadi nama resmi perusahaan pada tahun 1978. Berikut gambaran pembentukan Toshi
\end{abstract}

Kata Kunci : PERKEMBANGAN PRODUCT TOSHIBA 


\section{A. PENDAHULUAN}

Toshiba adalah salah satu perusahaan diversifikasi produsen dan pemasar produk digital, perangkat elektronik dan komponen, sistem infrastruktur sosial dan Home appliances. Sebagai pendiri dan inovator terkemuka dalam komputasi portabel dan produk-produk jaringan, Toshiba mulai memasarkan notebook, PC, dan PC server untuk rumah, kantor dan pengguna mobile. Toshiba Qosmio Notebook PC memimpin jalan dalam konvergensi komputasi dan kemampuan, menawarkan konsumen yang lengkap solusi hiburan pribadi. Sementara itu, seri "Tipis dan Ringan" membawa tingkat mobilitas tinggi dan daya tahan untuk notebook PC untuk penggunaan bisnis di era ini.

Toshiba memproduksi semua jenis laptop, dari model Libretto yang lucu dan ultra portabel sampai model multimedia Qosmio keren. Laptop Toshiba juga populer di Amerika dan Eropa. Apakah pengguna mencari pengganti desktop, laptop untuk mahasiswa atau laptop untuk game, akan ada sesuatu yang cocok bagi mereka di antara rangkaian yang tak terhitung jumlahnya seperti notebook Toshiba Libretto, Portege, Qosmio, Satellite dan Portege.

B. PEMBAHASAN / STUDI KASUS

Di zaman modern seperti ini sudah sangat banyak laptop toshiba yang beredar. Tapi bagaimanakah sejarah perkembangan laptop toshiba hingga bisa menjadi perusahaan besar??. Berikut akan dibahas perkembangan laptop toshiba dari zaman dahulu hingga sekarang.

\section{Toshiba T1100}

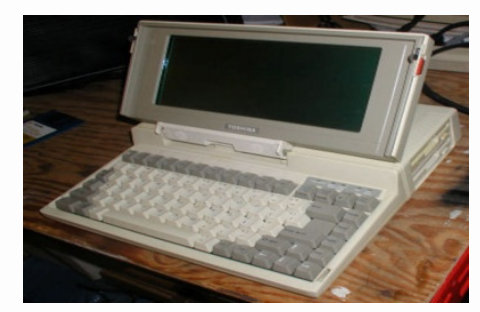

T1100 adalah laptop produksi Toshiba dan toshiba menyebutkan bahwa Laptop T1100 "the worlds first massmarket laptop computer". Spesifikasi teknis itu sebanding dengan IBM 
Original. Prosesor dari laptop ini menggunakan Intel 80C88, 4.77MHz

1986. Toshiba T3100

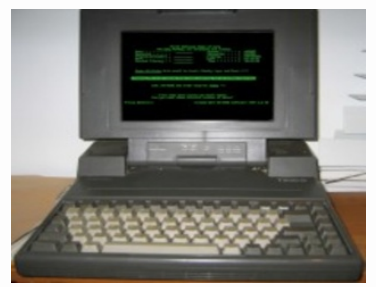

Laptop buatan toshiba tahun 1986 ini memiliki, $10 \mathrm{MB}$ Harddrive, $8 \mathrm{MHz}$ Intel 80286 CPU. Yoshiba mengatakan bahwa laptop ini adalah "World First Notebook PC with an Intel 286 Processor"

\section{Toshiba T3100 E}

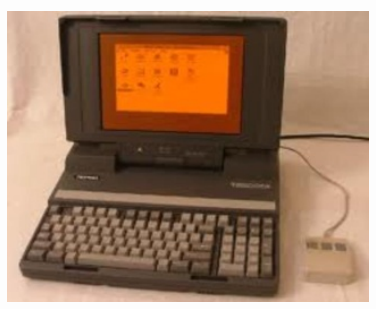

Laptop toshiba tahun keluaran 1988 inidisebut laptop pertama dunia yang menggunakan internal Hard Disk Drive dengan kapasitas 20MB.

1991. Toshiba T4400

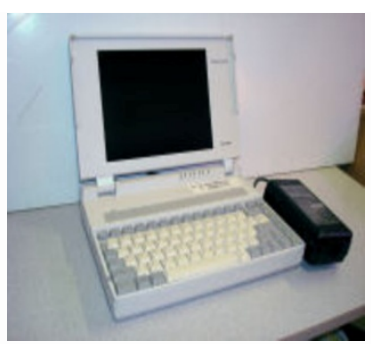

Laptop garapan Toshiba tahun 1991 ini dikatakan sebagai "World's First Notebook PC with an Active Matrix Screen"

\section{Toshiba Tecra CS/CDT}

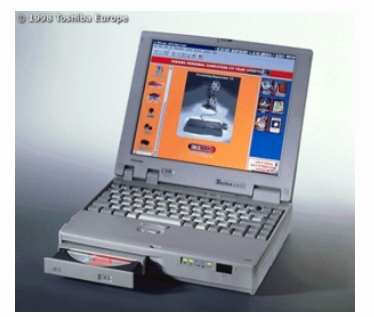

Lapop toshiba ini adalah laptop pertama dunia yang menggunakan intel pentium.

\section{Toshiba Tecra T6600 C}

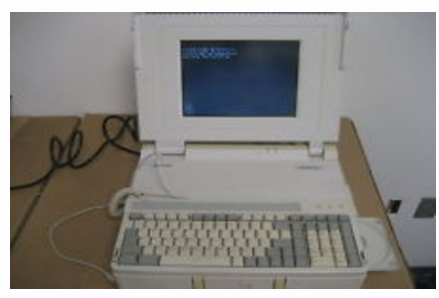

Laptop ini adalah laptop pertama dunia dengan menggunakan baterai Lithium 
-ion.

\section{Toshiba Libretto 50}

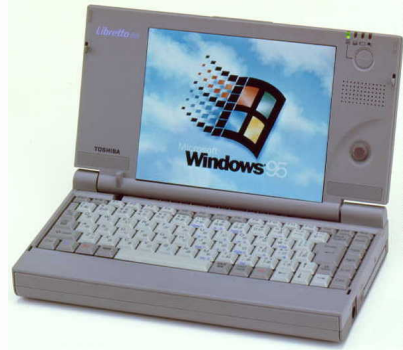

Laptop keluaran toshiba tahun 1997 ini adalah laptop pertama dunia yang menggunakan windows 95 secara penuh.

2001. Toshiba Portege 4000

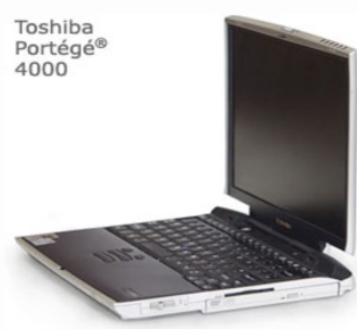

Laptop keluaran 2001 ini adalah laptop pertama di dunia dengan teknologi wireless. Laptop ini berkapastitas $20 \mathrm{~GB}$, dan baterai dari laptop ini dapat bertahan hidup 3,5 jam

2003. Toshiba Satellite P25 Series

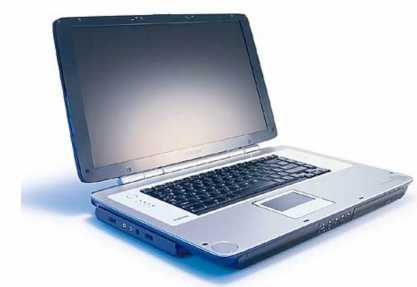

Laptop toshiba pertama di dunia dengan layar Widescreen 17 inch.

\section{Toshiba Tecra S3}

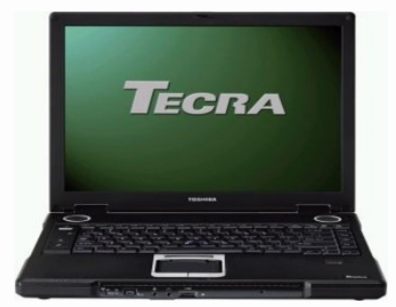

Laptop toshiba keluaran tahun 2005 ini adalah lapop pertama dunia dengan RoHSCompliant.

\section{Toshiba Protege R500}

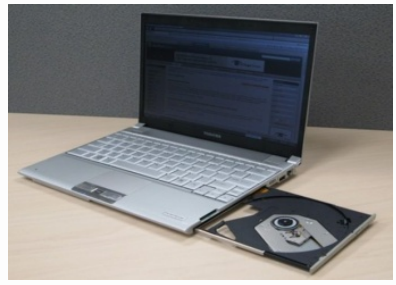

LAptop toshiba yang satu ini adalah laptop pertama dunia tertipis hanya dengan ketebalan $7 \mathrm{~mm}$ dan ukuran 12.1 inch dengan Super-Multi DVD drive. 


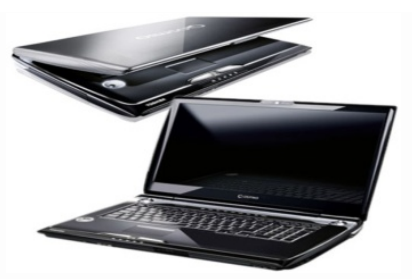

Qosimo G50 dari toshiba ini adalah laptop pertama dengan menggunakan prosesor quad-core di dunia.

2009. SSD 512 GB

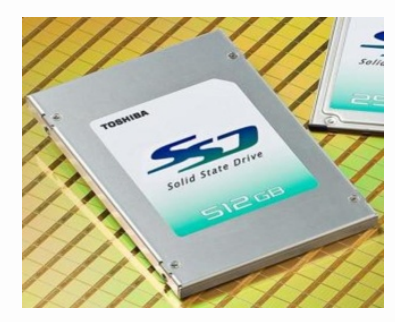

Ini adalah Ultra-portable pertama dengan kapasitas 512GB SSD

\section{Toshiba Libretto W100}

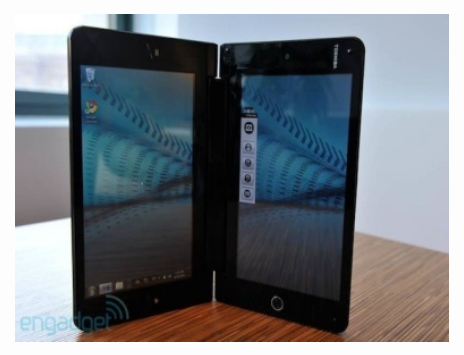

Toshiba Libretto W100, dual touch-screen ukuran 7 inch pertama di dunia. Bentuknya sangat unik.

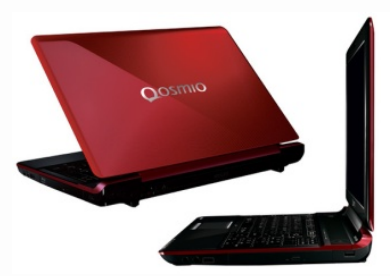

Toshiba Qosmio F750 adalah Laptop pertama di dunia yang berbasis 3D tapi tidak memerlukan kaca.

\section{Toshiba Protege $\mathrm{Z} 830$}

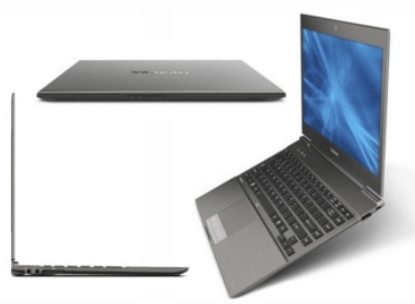

Protege Z830 adalah Ultrabook pertama di dunia yang memiliki konektivitas terlengkap.

\section{ID SECURITY \\ QWTD4452377-ASP- \\ 5244107}

\section{KESIMPULAN}

Toshiba yang jenis notebook inimemiliki produk berkualitas, berteknologi tinggi, dengan harga yang terjangkau, desain yang stylish, dan kinerja yang 
solid Toshiba Satellite adalah jawabannya. Laptop ini dapat menjalankan aplikasi bisnis paling kompleks, menyimpan dokumen yang besar, mempunyai file media digital dan software produktivitas.

\section{E. DISKUSI}

1.Apakah artikel ini membantu

anda..???

YUANITA :"sangat memmbantu karena saya bisa belajar tentang perkembangan product toshiba"

2.apakah kelebihan artikel ini ..???

ANANDA:"artikel ini dibuat nya dengan singkan dang jelas sehingga pembaca bisa mengerti dengan mudah

3.apa manfaat buat anda,setelah anda menbaca artikel ini...?

ZALMI :"manfaat bagi saya bias mennambah pengetahuan saya tentang perkembangan product toshiba

\section{F . REFERENCE}

[1] O. M. Febriani and A. S. Putra, "Sistem Informasi Monitoring Inventori Barang Pada Balai Riset Standardisasi Industri Bandar Lampung," J. Inform., vol. 13, no. 1, pp. 90-98, 2014.

[2] A. S. Putra, "Paperplain: Execution Fundamental Create Application With Borland Delphi 7.0 University Of Mitra Indonesia," 2018.

[3] A. S. Putra, "2018 Artikel Struktur Data, Audit Dan Jaringan Komputer," 2018.

[4] A. S. Putra, "ALIAS MANAGER USED IN DATABASE DESKTOP STUDI CASE DB DEMOS."

[5] A. S. Putra, "COMPREHENSIVE SET OF PROFESSIONAL FOR DISTRIBUTE COMPUTING."

[6] A. S. Putra, "DATA ORIENTED RECOGNITION IN BORLAND DELPHI 7.0."

[7] A. S. Putra, "EMBARCADERO DELPHI XE 2 IN GPUPOWERED FIREMONKEY APPLICATION."

[8] A. S. Putra, "HAK ATAS KEKAYAAN INTELEKTUAL DALAM DUNIA TEKNOLOGY BERBASIS REVOLUSI INDUSTRI 4.0."

[9] A. S. Putra, "IMPLEMENTASI PERATURAN PERUNDANGAN UU. NO 31 TAHUN 2000 TENTANG DESAIN INDUSTRI BERBASIS 
INFORMATION

TECHNOLOGY."

[10]

A.

$S$.

"IMPLEMENTATION

PARADOX DBASE."

[11] A.

$S$.

Putra,

OF

"IMPLEMENTATION

Putra,

TRADE SECRET CASE STUDY

SAMSUNG MOBILE PHONE."

[12] A

$\mathrm{S}$.

Putra,

"IMPLEMENTATION PATENT

FOR APPLICATION WEB

BASED CASE STUDI WWW. PUBLIKLAMPUNG. COM."

[13] A. $\mathrm{S}$.

Putra, "IMPLEMENTATION SYSTEM FIRST TO INVENT IN DIGITALLY INDUSTRY."

[14] A. S. Putra, "MANUAL REPORT \& INTEGRATED DEVELOPMENT

ENVIRONMENT BORLAND DELPHI 7.0."

[15] A. S. Putra, "PATENT AS RELEVAN SUPPORT RESEARCH."

[16] A. S. Putra, "PATENT FOR RESEARCH STUDY CASE OF APPLE. Inc."

[17] A. S. Putra, "PATENT PROTECTION FOR APPLICATION INVENT."

[18] A. S. Putra, "QUICK REPORT IN

PROPERTY

PROGRAMMING."

[19] A. S. Putra, "REVIEW CIRCUIT LAYOUT COMPONENT REQUIREMENT ON ASUS NOTEBOOK."

[20] A. S. Putra, "REVIEW TRADEMARK PATENT FOR INDUSTRIAL TECHNOLOGY BASED 4.0."

[21] A. S. Putra, "TOOLBAR COMPONENT PALLETTE IN
OBJECT ORIENTED PROGRAMMING."

[22] A. S. Putra, "WORKING DIRECTORY SET FOR PARADOX 7."

[23] A. S. Putra, "ZQUERY CONNECTION IMPLEMENTED

PROGRAMMING STUDI CASE PT. BANK BCA Tbk."

[24] A. S. Putra, D. R. Aryanti, and I. Hartati, "Metode SAW (Simple Additive Weighting) sebagai Sistem Pendukung Keputusan Guru Berprestasi (Studi Kasus: SMK Global Surya)," in Prosiding Seminar Nasional Darmajaya, 2018, vol. 1, no. 1, pp. 85-97.

[25] A. S. Putra and O. M. Febriani, "Knowledge Management Online Application in PDAM Lampung Province," in Prosiding International conference on Information Technology and Business (ICITB), 2018, pp. 181-187.

[26] A. S. Putra, O. M. Febriani, and B. Bachry, "Implementasi Genetic Fuzzy System Untuk Mengidentifikasi Hasil Curian Kendaraan Bermotor $\mathrm{Di}$ Polda Lampung," SIMADA (Jurnal Sist. Inf. dan Manaj. Basis Data), vol. 1, no. 1, pp. 21-30, 2018.

[27] A. S. Putra, H. Sukri, and K. Zuhri, "Sistem Monitoring Realtime Jaringan Irigasi Desa (JIDES) Dengan Konsep Jaringan Sensor Nirkabel," IJEIS (Indonesian J. Electron. Instrum. Syst., vol. 8, no. 2, pp. 221-232.

[28] D. P. Sari, O. M. Febriani, and 

A. S. Putra, "Perancangan
Sistem Informasi SDM
Berprestasi pada SD Global
Surya," in Prosiding Seminar
Nasional Darmajaya, 2018,
vol. 1, no. 1, pp. 289-294. 